\title{
Emerging Therapeutic Potential of Mesenchymal Stem Cell-Derived Extracellular Vesicles in Chronic Respiratory Diseases: An Overview of Recent Progress
}

\author{
Yiming Ma, Xiangming Liu, Yingjiao Long * and Yan Chen*
}

Department of Pulmonary and Critical Care Medicine, The Second Xiangya Hospital, Central South University, Changsha, China

Mesenchymal stem cell-derived extracellular vesicles (MSC-EVs) are able to carry genetic and protein goods to mediate the interaction between MSCs and target cells. Recently, more and more researches have focused on the therapeutic role of MSC-EVs

OPEN ACCESS

Edited by:

Hong Yang,

Tianjin Medical University, China

Reviewed by:

Zhigang Cai,

Tianjin Medical University, China

Wenjun Mao,

The affiliated Wuxi People's Hospital of

Nanjing Medical University, China

*Correspondence:

Yan Chen

chenyan99727@csu.edu.cn

Yingjiao Long

longyingjiao@csu.edu.cn

Specialty section:

This article was submitted to

Nanobiotechnology,

a section of the journal

Frontiers in Bioengineering and

Biotechnology

Received: 29 December 2021

Accepted: 31 January 2022

Published: 25 February 2022

Citation:

Ma Y, Liu X, Long Y and Chen Y (2022) Emerging Therapeutic Potential of

Mesenchymal Stem Cell-Derived

Extracellular Vesicles in Chronic Respiratory Diseases: An Overview of

Recent Progress.

Front. Bioeng. Biotechnol. 10:845042.

doi: 10.3389/fbioe.2022.845042 in chronic respiratory diseases. In this review, we summarize the cumulative strategies and mechanisms of MSC-EVs in treating chronic respiratory diseases. This review suggests that MSC-EVs may serve as a novel cell-free-based therapy for chronic respiratory diseases, including COPD, asthma, pulmonary fibrosis, and pulmonary arterial hypertension. In current studies of chronic respiratory diseases, umbilical cord and bone marrow are main sources of MSC-EVs, while adipose tissue, lung, and induced pluripotent stem cells are also applied. Isolation methods of MSC-EVs in treating chronic respiratory diseases involve ultracentrifugation, exosome extraction kits and anion-exchange chromatography. Intratracheal delivery and intravenous administration are the most widely used routes of MSC-EVs. MSC-EVs are able to transfer microRNAs and protein to target cells and further magnify the therapeutic effects.

Keywords: mesenchymal stem cell, extracellular vesicle, chronic respiratory disease, therapy, microRNA

\section{INTRODUCTION}

Chronic respiratory diseases are diseases of the airways and other structures of the lung, mainly including chronic obstructive pulmonary disease (COPD), asthma, occupational lung diseases and pulmonary hypertension (World Health Organization, 2021). Chronic respiratory diseases remain leading causes of death and disability. It is estimated that 4 million people per year die from chronic respiratory diseases worldwide (Forum of International Respiratory Societies, 2017; Soriano et al., 2020). Considering the

\footnotetext{
Abbreviations: MSCmesenchymal stem cell; EVs-extracellular vesicles; COPD-chronic obstructive pulmonary disease; UCumbilical cord; PRKCZ -protein kinase C zeta; TRAF1-tumor necrosis factor receptor associated factor 1; iPSC-induced pluripotent stem cell; ILC2-group 2 innate lymphoid cells; UCF-ultracentrifugation; PBMCs-peripheral blood mononuclear cells; Tregs-regulatory T cells; SOX4-sky box transcription factor 4; DKK1-Dickkopf Wnt signaling pathway inhibitor 1; HuBEC-human basal bronchial epithelial cell; FZD6-frizzled class receptor 6; AMSC-adipose derived mesenchymal stem cell; ATII-alveolar epithelial type II; HBEC-human bronchial epithelial cell; PPAR-peroxisome proliferator-activated receptor; PAH-pulmonary arterial hypertension.
} 
heavy social burden from chronic respiratory diseases, effective prevention and treatment measures are urgently needed.

Mesenchymal stem cells (MSCs) refer to a group of cells from bone marrow, fat and umbilical cord, which have the ability of adherent growth. Currently, MSCs are commonly used in cell therapy due to important potentials of proliferation, differentiation and immune regulation (Weiss and Dahlke, 2019). Extracellular vesicles (EVs) are vesicles with membrane structure released by cells in the state of activation, injury or apoptosis; According to the diameter of vesicles, they can be divided into apoptotic bodies, micro vesicles, and exosomes (Shao et al., 2018). A growing number of studies have shown that EVs mediate intercellular targeted regulation by transferring different substances (including protein, DNA, microRNA, lncRNA, circRNA and mRNA) (Lasda and Parker, 2016; Li et al., 2019; Vagner et al., 2019; Vu et al., 2020; Vilaca et al., 2021). Importantly, compared with other commonly used drug delivery carriers (such as liposomes), EVs have the advantages of high internal targeting ability, low immunogenicity, high modification flexibility and high biological barrier permeability, which opens up a new field for modern drug delivery (Herrmann et al., 2021).

MSCs can produce a large number of EVs. MSC-EVs can mediate the interaction between MSCs and target cells through delivering genetic and protein goods, and this targeting mode has attracted great attention in the treatment of chronic kidney diseases, cardiovascular diseases, neurological diseases and tumor (Eirin and Lerman, 19792021; Fu et al., 2020; Tran et al., 2020; Pucci et al., 2021)) MSC-EVs can play a therapeutic role similar to MSCs, and MSC-EVs are easier to store and make dosage forms; Meanwhile, MSC-EVs avoid some limitations of cell therapy, such as embolization and tumorigenesis (Shi et al., 2021). The potential antiinflammatory effect of MSC-EVs has been proved in several previous studies related to acute lung injury (Monsel et al., 2015; Ahn et al., 2018; Khatri et al., 2018). Recently, more and more researches have focused on the therapeutic role of MSCEVs in chronic respiratory diseases. In this review, we summarize the cumulative strategies and mechanisms of MSC-EVs in treating chronic respiratory diseases, which may provide novel therapeutic alternatives for chronic respiratory diseases.

\section{SOURCES OF MESENCHYMAL STEM CELL-DERIVED EXTRACELLULAR VESICLES IN THERAPEUTIC APPLICATIONS OF CHRONIC RESPIRATORY DISEASES}

Umbilical cord (UC) and bone marrow (BM) are main sources of MSC-EVs in treating chronic respiratory diseases, while other relatively rare sources include adipose tissue, lung, and induced pluripotent stem cells (iPSCs).

UC is an appropriate source of MSC-EVs, with the advantage of non-invasion in the collecting process of UC (de Faria et al., 2012). BM may be suboptimal, as BM-MSCs have shown decreased differentiation potential and $\mathrm{BM}$ samples are rather difficult in acquisition (Sergejeva et al., 2004). Of note, the use of adipose tissues to harvest MSCs has become common due to its unique advantages such as easy access, great texture and rapid expansion in vitro (Bertassoli et al., 2013; Jalali and Rabiee, 2016). However, few studies have investigated the therapeutic functions of MSC-EVs from adipose tissues in chronic respiratory diseases. Lung is another source of MSC-EVs. Cells derived from human lung allografts present a multipotent mesenchymal cell population, which is locally resident in the human adult lung and has extended life span in vivo; And multipotency of these cells was proved by their capacity to differentiate into adipocytes, chondrocytes, and osteocytes (Lama et al., 2007). iPSCs are also sources of MSC-EVs, and MSC-EVs from iPSCs can be utilized for drug delivery by loading with proteins (Yuan et al., 2017). iPSCs maintain the developmental potential to differentiate into advanced derivatives of all three primary germ layers, which provides a novel direction of regenerative medicine.

\section{SOLATION METHODS OF MESENCHYMAL STEM CELL-DERIVED EXTRACELLULAR VESICLES IN THERAPEUTIC APPLICATIONS OF CHRONIC RESPIRATORY DISEASES}

Methods used to isolate MSC-EVs in treating chronic respiratory diseases involve ultracentrifugation (UCF), exosome extraction kits and anion-exchange chromatography.

UCF is the current gold standard and the most studied methods for EV isolation (Momen-Heravi, 2017). The centrifugal speed for microvesicles is 10,000-60,000 g, while 100,000-200,000 g for exosomes (Borges et al., 2013). However, UCF is time-consuming and isolation outcomes are also highly dependent on speed, rotor type as well as temperature (Livshits et al., 2015). Also, UCF could lead to aggregated EVs after pelleting (Linares et al., 2015). Exosome extraction kits are emerging tools for exosome isolation. One previous study demonstrated that ultracentrifugation and exosome extraction kits are two complementary approaches allowing the detection of different proteoforms with various abundance and purity levels (Gemoll et al., 2020). Thereby, combined isolation methods may be optional to consider in future studies. Anion-exchange chromatography is a scalable protocol developed by Kim et al., in 2016 (Kim et al., 2016). They found that most of the protein from EVs in the harvested medium was bound to an anion exchange resin but that little bound to a cation exchange resin. Besides above mentioned methods, additional techniques or combinations of techniques have been developed to isolate EVs including field-flow fractionation, variations on size exclusion chromatography, microfiltration, asymmetric flow field-flow fractionation, field-free viscoelastic flow, tangential flow filtration and variations thereon, alternating current electrophoretics, deterministic lateral displacement arrays, fluorescence-activated sorting, novel immunoisolation or other affinity isolation technologies etc. (Théry et al., 2018) 
TABLE 1 | Therapeutic applications of MSC-derived EVs in chronic lung diseases.

\begin{tabular}{|c|c|c|c|c|c|c|}
\hline References & Year & Disease & EV source & Isolation method & Therapeutic strategy & Mechanisms \\
\hline $\begin{array}{l}\text { Ridzuan et al. } \\
\text { (2021) }\end{array}$ & 2021 & COPD & Human UC-MSCs & UCF & $\begin{array}{l}\text { In vivo: EVs from } 2.5 \times 10^{6} \mathrm{MSCs} \\
\text { over } 72 \mathrm{~h} \text { per rat; once; } \\
\text { intratracheal delivery }\end{array}$ & $\begin{array}{l}\text { EVs reduce the pulmonary } \\
\text { inflammation by the expression of } \\
\text { PRKCZ, and NF- } \mathrm{KB} \text { subunits p65 } \\
\text { and p50 }\end{array}$ \\
\hline $\begin{array}{l}\text { Maremanda } \\
\text { et al. (2019) }\end{array}$ & 2018 & COPD & Mouse MSCs & Norgen Biotek kit & $\begin{array}{l}\text { In vivo: } 15 \mu \mathrm{g} \text { (protein) EVs per } \\
\text { mouse; daily for } 10 \text { days; } \\
\text { intraperitoneal route In vitro: not } \\
\text { reported }\end{array}$ & $\begin{array}{l}\text { EVs protect cigarette smoke-induced } \\
\text { inflammation and mitochondrial } \\
\text { dysfunction }\end{array}$ \\
\hline $\begin{array}{l}\text { Dong et al. } \\
(2021)\end{array}$ & 2021 & Asthma & Human UC-MSCs & $\begin{array}{l}\text { exoEasy Maxi Kit } \\
\text { (Qiagen) }\end{array}$ & $\begin{array}{l}\text { In vivo: } 100 \text { mg (protein) EVs per } \\
\text { mouse; once; intratracheal delivery } \\
\text { In vitro: } 10,20,40 \mu \mathrm{g} / \mathrm{ml} \mathrm{EVs} \\
\text { added to macrophages for } 24 \mathrm{~h}\end{array}$ & $\begin{array}{l}\text { EVs inhibit inflammation by reshaping } \\
\text { macrophage polarization via inhibition } \\
\text { of TRAF1 }\end{array}$ \\
\hline $\begin{array}{l}\text { Fang et al. } \\
\text { (2020a) }\end{array}$ & 2020 & Asthma & Human iPSC-MSCs & $\begin{array}{l}\text { Anion-exchange } \\
\text { chromatography }\end{array}$ & $\begin{array}{l}\text { In vivo: } 1.5 \times 10^{10} \mathrm{EV} \text { s per mouse; } \\
\text { once; intravenous administration } \\
\text { In vitro: } 5 \times 10^{8} \mathrm{EVs} \text { added to } \\
3 \times 10^{5} \text { macrophages }\end{array}$ & $\begin{array}{l}\text { EVs ameliorate Th2-dominant allergic } \\
\text { airway inflammation through } \\
\text { immunoregulation on pulmonary } \\
\text { macrophages }\end{array}$ \\
\hline $\begin{array}{l}\text { Fang et al. } \\
\text { (2020b) }\end{array}$ & 2020 & Asthma & Human iPSC-MSCs & $\begin{array}{l}\text { Anion-exchange } \\
\text { chromatography }\end{array}$ & $\begin{array}{l}\text { In vivo: } 2 \times 10^{10} \mathrm{EVs} \text { per mouse; } \\
\text { once; intravenous administration } \\
\text { In vitro: } 5,40 \mu \mathrm{g} / \mathrm{ml} \text { EVs added to } \\
\text { ILC2 for } 48 \mathrm{~h}\end{array}$ & $\begin{array}{l}\text { EVs prevent ILC2-dominant allergic } \\
\text { airway inflammation by transferring } \\
\text { miR-146a-5p }\end{array}$ \\
\hline Du et al. (2018) & 2018 & Asthma & Human BM-MSCs & UCF & $\begin{array}{l}\text { In vitro: EVs from } 1 \times 10^{5} \mathrm{MSCs} \\
\text { over } 48 \mathrm{~h} \text { added to } 1 \times 10^{6} \\
\text { PBMCs for } 48 \mathrm{~h}\end{array}$ & $\begin{array}{l}\text { EVs upregulate } \mathrm{IL}-10 \text { and TGF- } \beta 1 \text { in } \\
\text { PBMCs, and promote proliferation and } \\
\text { immune-suppression capacity of Tregs }\end{array}$ \\
\hline $\begin{array}{l}\text { Zhang et al. } \\
\text { (2021) }\end{array}$ & 2021 & Pulmonary fibrosis & Rat BM-MSCs & UCF & $\begin{array}{l}\text { In vivo: } 100 \mu \mathrm{g} \text { (protein) EVs per } \\
\text { rat; once; intravenous } \\
\text { administration }\end{array}$ & $\begin{array}{l}\text { EVs reverse epithelial mesenchymal } \\
\text { transition through Wnt/ } \beta \text {-catenin } \\
\text { signaling }\end{array}$ \\
\hline $\begin{array}{l}\text { Zhou et al. } \\
\text { (2021) }\end{array}$ & 2021 & Pulmonary fibrosis & Human BM-MSCs & UCF & $\begin{array}{l}\text { In vivo: } 100 \mu \mathrm{g} \text { (protein) EVs per } \\
\text { mouse; once; intravenous } \\
\text { administration } \\
\text { In vitro: } 10 \mu \mathrm{g} \text { EV added to } \\
3-5 \times 10^{5} \text { fibroblast for } 24 \mathrm{~h}\end{array}$ & $\begin{array}{l}\text { EVs block fibroblast activation and } \\
\text { suppress SOX } 4 \text {, DKK1 expression by } \\
\text { transferring miR-186 }\end{array}$ \\
\hline $\begin{array}{l}\text { Villamizar et al. } \\
\text { (2021) }\end{array}$ & 2020 & Cystic fibrosis & Human BM-MSCs & UCF & $\begin{array}{l}\text { In vitro: } 5 \times 10^{10} \mathrm{EVs} \text { added to } 10^{4} \\
\text { HuBECs for } 48 \mathrm{~h}\end{array}$ & $\begin{array}{l}\text { EVs deliver a packaged zinc finger } \\
\text { activator to HuBECs and activate } \\
\text { CFTR }\end{array}$ \\
\hline Xu et al. (2020) & 2020 & Pulmonary fibrosis & Human UC-MSCs & $\begin{array}{l}\text { Exoquick exosome } \\
\text { precipitation solution } \\
\text { (System }\end{array}$ & $\begin{array}{l}\text { In vivo: unknown dose; every } 4 \\
\text { days; intravenous administration } \\
\text { In vitro: not reported }\end{array}$ & $\begin{array}{l}\text { EVs decrease collagen I and } \\
\text { fibronectin, and improve pulmonary } \\
\text { function }\end{array}$ \\
\hline $\begin{array}{l}\text { Yang et al. } \\
(2020)\end{array}$ & 2020 & Pulmonary fibrosis & Human UC-MSCs & Biosciences) & $\begin{array}{l}\text { In vivo: } 100 \text { Mg (protein) EVs per } \\
\text { mouse; every } 4 \text { days; intravenous } \\
\text { administration }\end{array}$ & $\begin{array}{l}\text { EVs inhibit epithelial mesenchymal } \\
\text { transition activated by the TGF- } \beta 1 / \\
\text { Smad2/3 signaling pathway }\end{array}$ \\
\hline $\begin{array}{l}\text { Wan et al. } \\
(2020)\end{array}$ & 2020 & Pulmonary fibrosis & Human BM-MSCs & UCF & $\begin{array}{l}\text { In vivo: } 100 \mu \mathrm{g} \text { (protein) EVs per } \\
\text { mouse; once; intravenous } \\
\text { administration } \\
\text { In vitro: } 10 \mu \mathrm{g} \text { EV added to } \\
3-5 \times 10^{5} \text { fibroblast for } 24 \mathrm{~h}\end{array}$ & $\begin{array}{l}\text { EVs suppress the fibroblast } \\
\text { proliferation by downregulating FZD6 } \\
\text { expression in fibroblasts via carrying } \\
\text { miR-29b-3p }\end{array}$ \\
\hline $\begin{array}{l}\text { Gao et al. } \\
(2020)\end{array}$ & 2020 & Pulmonary fibrosis & Rat AMSCs & UCF & $\begin{array}{l}\text { In vivo: } 2.5-2.8 \times 10^{10} \mathrm{EVs} \text { per rat; } \\
\text { once; intratracheal delivery } \\
\text { In vitro: } 1 \times 10^{9} \mathrm{EVs} \text { added to } \\
1 \times 10^{6} \mathrm{ATII} \text { cells for } 6 \mathrm{~h}\end{array}$ & $\begin{array}{l}\text { EVs inhibit TGF-bRI by transferring let- } \\
7 d-5 p\end{array}$ \\
\hline $\begin{array}{l}\text { Zulueta et al. } \\
\text { (2018) }\end{array}$ & 2018 & Cystic fibrosis & Human lung MSCs & UCF & $\begin{array}{l}\text { In vitro: EVs from } 3 \times 10^{6} \text { MSCs } \\
\text { over } 48-72 \mathrm{~h} \text { added to } 2.5 \times 10^{5} \\
\text { HBECs for } 30 \mathrm{~h}\end{array}$ & $\begin{array}{l}\text { EVs upregulate PPAR } \gamma \text {, a transcription } \\
\text { factor controlling anti-inflammatory and } \\
\text { antioxidant mechanisms via NF-kB and } \\
\mathrm{HO}-1\end{array}$ \\
\hline $\begin{array}{l}\text { Klinger et al. } \\
(2020)\end{array}$ & 2020 & $\mathrm{PAH}$ & MSCs & UCF & $\begin{array}{l}\text { In vivo: } 100 \mathrm{mg} / \mathrm{kg} \text { EVs per rat; } \\
\text { three times; intravenous } \\
\text { administration } \\
\text { In vitro: } 0,2,5 \text {, and } 10 \mu \mathrm{g} / \mathrm{ml} \mathrm{EVs} \\
\text { added to macrophages for } 48 \mathrm{~h}\end{array}$ & $\begin{array}{l}\text { EVs decrease lung macrophages, } \\
\text { increase the ratio of M2/M1 } \\
\text { macrophages, normalize right } \\
\text { ventricular pressure and reduce right } \\
\text { ventricular hypertrophy and } \\
\text { muscularization of peripheral } \\
\text { pulmonary vessels }\end{array}$ \\
\hline $\begin{array}{l}\text { Zhang et al. } \\
\text { (2020) }\end{array}$ & 2020 & $\mathrm{PAH}$ & Human UC-MSCs & UCF & $\begin{array}{l}\text { In vivo: } 25 \mu \mathrm{g} \text { EV per rat; three } \\
\text { times; intravenous administration } \\
\text { In vitro: not reported }\end{array}$ & $\begin{array}{l}\text { EVs inhibit hypoxia-induced pulmonary } \\
\text { arterial endothelial cell apoptosis, } \\
\text { pulmonary arterial smooth muscle cells } \\
\text { proliferation, and pulmonary arterioles } \\
\text { endothelial-to-mesenchymal transition } \\
\text { by upregulating the expression of } \\
\text { Wnt5a } \\
\text { (Continued on following page) }\end{array}$ \\
\hline
\end{tabular}


TABLE 1 | (Continued) Therapeutic applications of MSC-derived EVs in chronic lung diseases.

\begin{tabular}{|c|c|c|c|c|c|c|}
\hline References & Year & Disease & EV source & Isolation method & Therapeutic strategy & Mechanisms \\
\hline Liu et al. (2018) & 2018 & $\mathrm{PAH}$ & Rat BM-MSCs & UCF & 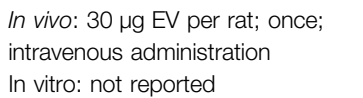 & $\begin{array}{l}\text { EVs relieve } \mathrm{PAH} \text { by regulating renin- } \\
\text { angiotensin system }\end{array}$ \\
\hline $\begin{array}{l}\text { Hogan et al. } \\
\text { (2019) }\end{array}$ & 2018 & $\mathrm{PAH}$ & Human BM-MSCs & Not reported & $\begin{array}{l}\text { In vivo: } 2 \times 10^{7} \text { EVs per mouse; } \\
\text { once; intravenous administration } \\
\text { In vitro: } 2 \times 10^{7} \mathrm{EV} \text { added to } \\
\text { PASMCs in a } 6 \text {-well plate biweekly } \\
\text { on culture days } 1,4,8 \text {, and } 11\end{array}$ & $\begin{array}{l}\text { EVs relieve PAH by improving } \\
\text { mitochondrial function }\end{array}$ \\
\hline $\begin{array}{l}\text { Chen et al. } \\
\text { (2014) }\end{array}$ & 2014 & $\mathrm{PAH}$ & Rat BM-MSCs & UCF & $\begin{array}{l}\text { In vivo: } 30 \text { mg (protein) EVs per rat; } \\
\text { on alternate days for } 2 \text { weeks; } \\
\text { intravenous administration }\end{array}$ & $\begin{array}{l}\text { EVs relieve PAH (without specific } \\
\text { mechanisms) }\end{array}$ \\
\hline
\end{tabular}

MSC, mesenchymal stem cell; EVs-extracellular vesicles; COPD-chronic obstructive pulmonary disease; UC-umbilical cord; PRKCZ -protein kinase C zeta; TRAF1-tumor necrosis factor receptor associated factor 1; iPSC-induced pluripotent stem cell; ILC2-group 2 innate lymphoid cells; UCF-ultracentrifugation; PBMCs-peripheral blood mononuclear cells; Tregsregulatory T cells; SOX4-sky box transcription factor 4; DKK1-Dickkopf Wnt signaling pathway inhibitor 1; HuBEC-human basal bronchial epithelial cell; FZD6-frizzled class receptor 6; AMSC-adipose derived mesenchymal stem cell; ATII-alveolar epithelial type II; HBEC-human bronchial epithelial cell; PPAR-peroxisome proliferator-activated receptor; PAH-pulmonary arterial hypertension.

\section{THERAPEUTIC STRATEGIES OF MESENCHYMAL STEM CELL-DERIVED EXTRACELLULAR VESICLES IN TREATING CHRONIC RESPIRATORY DISEASES}

The dose of MSC-EVs varies in different disease models. Most studies measured total protein amount using various colorimetric assays to indirectly suggest the particle number of EVs. In vivo, 15-100 $\mu \mathrm{g}$ (protein) is the commonly used EV dose for treating mouse or rat models; while $2-40 \mu \mathrm{g} / \mathrm{ml}$ is the usual treatment dose for studies in vitro. Some studies used absolute particle count or MSC number to measure EV treatment dose. The absolute particle count of EVs ranges from $2 \times 10^{7}$ to $2 \times 10^{10}$ in vivo.

Intratracheal delivery and intravenous administration are main routes of MSC-EVs in the treatment of chronic respiratory diseases. Compared with intravenous administration, intratracheal administration is a more direct and accurate treatment mode (Chen et al., 2021). An intraperitoneal route could be selected based on its advantages for multiple or daily treatments of EVs (Maremanda et al., 2019). Details of therapeutic strategies of MSC-EVs in treating chronic respiratory diseases are demonstrated in Table 1.

\section{MECHANISMS OF MESENCHYMAL STEM CELL-DERIVED EXTRACELLULAR VESICLES ON THERAPEUTIC APPLICATIONS OF CHRONIC RESPIRATORY DISEASES}

\section{Chronic Obstructive Pulmonary Disease}

Previous studies have proved the therapeutic role of MSC-EVs in COPD. Maremanda et al.(Maremanda et al., 2019) reported that exosomes from mouse MSCs could relieve cigarette smokeinduced inflammation and mitochondrial dysfunction in mice and human lung epithelial cells. A recent study demonstrated that
EVs from human UC-MSCs were able to reduce both peribronchial and perivascular inflammation, and subsequent microarray analysis revealed that EVs significantly regulate multiple known pathways associated with COPD, including TGF- $\beta$ receptor signaling pathway, IL-4 signaling pathway, and TNF alpha NF-kB signalling pathway (Ridzuan et al., 2021).

\section{Asthma}

The therapeutic role of MSC-EVs in asthma has been investigated both in vitro and in vivo. Dong et al. (Dong et al., 2021) found that human UC-MSCs derived EVs inhibited inflammation by reshaping macrophage polarization via blocking tumor necrosis factor receptor associated factor 1 (TRAF1). Fang et al. (Fang et al., 2020a) also investigated effects of MSC-EVs on macrophages in asthma disease model, and their research suggested that EVs from human iPSC-MSCs inhibited the recruitment and polarization of lung macrophages in mice with allergic airway inflammation. Another study by Fang et al. (Fang et al., 2020b) indicated that MSC-EVs prevented group 2 innate lymphoid cells (ILC2)-dominant allergic airway inflammation in mice, and the anti-inflammatory effect might contribute from transferred miR-146a-5p in MSC-EVs. EVs from human BM-MSCs might also have a therapeutic effect on asthma. Du et al. (Du et al., 2018) revealed that human BMMSCs derived EVs upregulated IL-10 and TGF- $\beta 1$ in peripheral blood mononuclear cells (PBMCs), and promoted proliferation, immune-suppression capacity of regulatory $\mathrm{T}$ cells (Tregs).

\section{Pulmonary Fibrosis}

A growing number of studies have demonstrated that MSC-EVs also play a therapeutic role in pulmonary fibrosis. Xu et al. (Xu et al., 2020) indicated that human UC-MSCs derived EVs could decrease collagen I and fibronectin, and improve pulmonary function. Two Chinese studies proved that EVs from rat BMMSCs and human UC-MSCs reversed epithelial mesenchymal transition, and the inhibition effect might be related to $\mathrm{Wnt} / \beta$ catenin signaling and TGF- $\beta 1 / \mathrm{Smad} 2 / 3$ pathway (Yang et al., 2020; Zhang et al., 2021). 


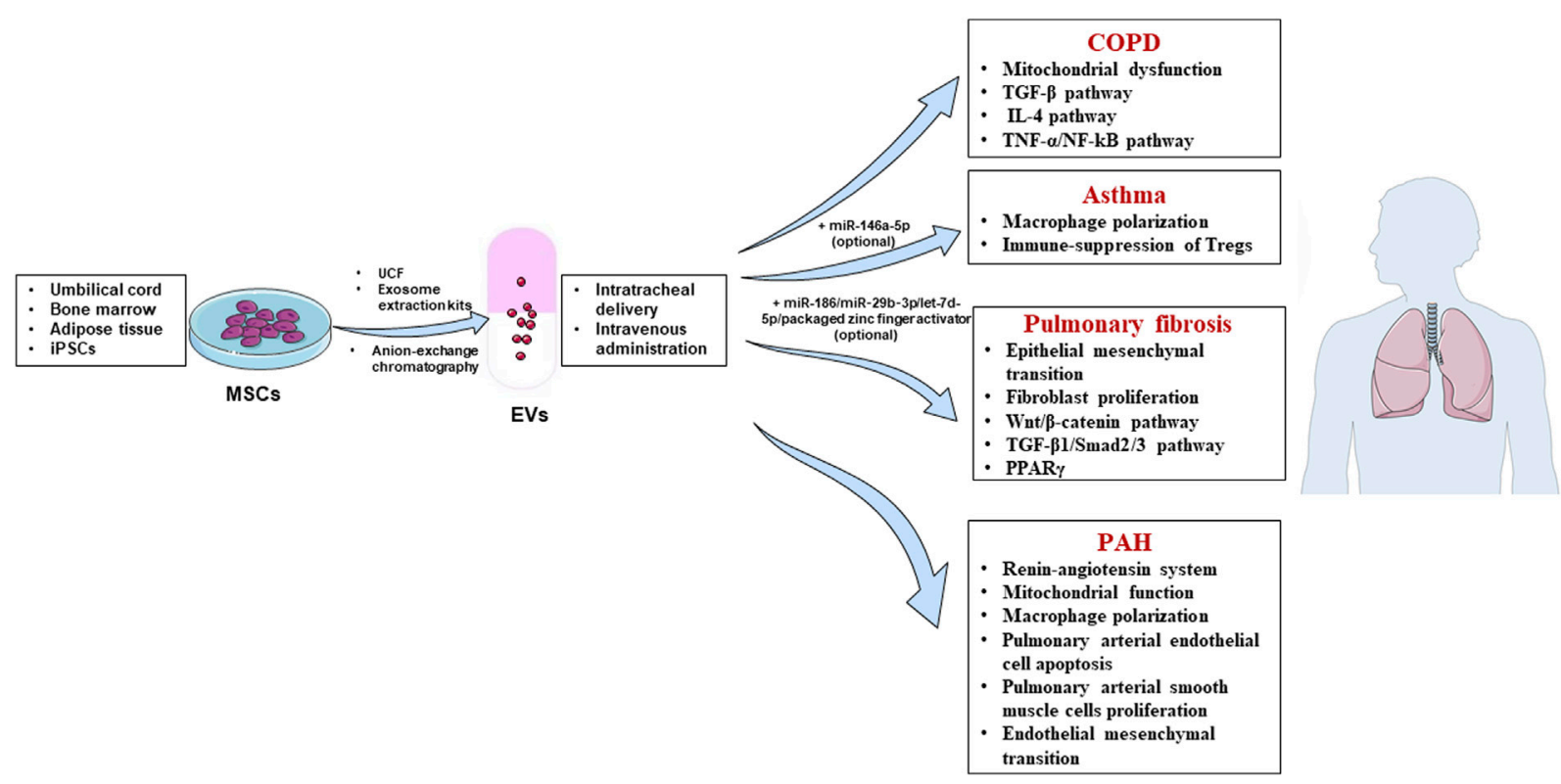

FIGURE 1 | Mechanisms of mesenchymal stem cell-derived extracellular vesicles (MSC-EVs) in treating chronic respiratory diseases. Sources of MSC-EVs: umbilical cord, bone marrow, adipose tissue and induced pluripotent stem cells (iPSCs); Isolation methods: ultracentrifugation (UCF), exosome extraction kits and anionexchange chromatography; Treatment routes: intratracheal delivery and intravenous administration; Diseases: chronic obstructive pulmonary disease (COPD), asthma, pulmonary fibrosis and pulmonary arterial hypertension (PAH).

Three studies indicated MSC-EVs inhibited pulmonary fibrosis by transferring microRNAs. Zhou et al. (Zhou et al., 2021) found that EVs from human BM-MSCs blocked fibroblast activation and suppressed SOX4, DKK1 expression by transferring miR-186. Human BM-MSCs derived EVs could also suppress the fibroblast proliferation by downregulating FZD6 expression via carrying miR-29b-3p (Wan et al., 2020). And Gao et al. (Gao et al., 2020) reported that EVs from rat adipose derived mesenchymal stem cells (AMSCs) inhibited TGF-bRI by transferring let-7d-5p in alveolar epithelial cells. MSC-EVs also transferred protein to relieve pulmonary fibrosis. One study by Villamizar et al. (Villamizar et al., 2021) illustrated that EVs from human BM-MSCs were able to deliver a packaged zinc finger activator to human basal bronchial epithelial cells (HuBECs) and activate cystic fibrosis transmembrane conductance regulator (CFTR).

Furthermore, human lung MSC-EVs could upregulate $\operatorname{PPAR} \gamma$, a transcription factor controlling anti-inflammatory and antioxidant mechanisms via $\mathrm{NF}-\kappa \mathrm{B}$ and $\mathrm{HO}-1$, and prevent cystic fibrosis in vitro (Zulueta et al., 2018).

\section{Pulmonary Arterial Hypertension}

Previous studies also investigated the role of MSC-EVs in treating $\mathrm{PAH}$, and the main source of EVs is BM-MSCs. Both rat BM MSC-EVs and human BM MSC-EVs demonstrated therapeutic effects on $\mathrm{PAH}$ disease models (Chen et al., 2014; Liu et al., 2018; Hogan et al., 2019), and involved mechanisms included regulating renin-angiotensin system and improving mitochondrial function. Besides, Klinger et al. (Klinger et al., 2020) found that MSC-EVs decreased lung macrophages, increased the ratio of $\mathrm{M} 2 / \mathrm{M} 1$ macrophages, normalized right ventricular pressure, and reduced right ventricular hypertrophy and muscularization of peripheral pulmonary vessels. And EVs originated from human UC-MSCs could inhibit hypoxia-induced pulmonary arterial endothelial cell apoptosis, pulmonary arterial smooth muscle cells proliferation, and pulmonary arterioles endothelial-tomesenchymal transition by upregulating the expression of Wnt5a (Zhang et al., 2020).

Mechanisms of MSC-EVs in chronic respiratory diseases are summarized in Figure 1.

\section{CONCLUSIONS AND FUTURE DIRECTIONS}

Collectively, emerging findings reveal that MSC-EVs may serve as a novel cell-free-based therapy for chronic respiratory diseases, including COPD, asthma, pulmonary fibrosis, and pulmonary arterial hypertension. Bone marrow and umbilical cord are main sources of MSC-EVs in treating chronic respiratory diseases, while adipose tissue, lung, and induced pluripotent stem cells are also applied. Isolation methods of MSC-EVs in treating chronic respiratory diseases involve ultracentrifugation, exosome extraction kits and anion-exchange chromatography. As for treatment routes of MSC-EVs, intratracheal delivery and intravenous administration are most widely used. Current studies suggest that MSC-EVs are able to transfer microRNAs and protein to target cells and further magnify the therapeutic effects. However, existing studies have not compared treatment effects among MSC-EVs from different sources (umbilical cord, 
bone marrow, adipose tissue and induced pluripotent stem cells) or types (apoptotic bodies, microvesicles and exosomes), which highly prompt future studies to address this item. Novel administration routes of MSC-EVs, such as nebulized inhalation, are also worthy of attention so as to improve the safety and effectiveness of MSC-EVs in the treatment of chronic respiratory diseases. Moreover, future studies through nucleic acid sequencing and proteomics are still warranted to reveal internal components of MSC-EVs from various sources and explicit mechanisms of MSC-EVs treatment on different chronic respiratory disease models.

\section{REFERENCES}

Ahn, S. Y., Park, W. S., Kim, Y. E., Sung, D. K., Sung, S. I., Ahn, J. Y., et al. (2018). Vascular Endothelial Growth Factor Mediates the Therapeutic Efficacy of Mesenchymal Stem Cell-Derived Extracellular Vesicles against Neonatal Hyperoxic Lung Injury. Exp. Mol. Med. 50 (4), 1-12. doi:10.1038/s12276018-0055-8

Bertassoli, B. M., Assis Neto, A. C. d., Oliveira, F. D. d., Arroyo, M. A. M., Ferrão, J. S. P., Silva, J. B. d., et al. (2013). Mesenchymal Stem Cells: Emphasis in Adipose Tissue. Braz. Arch. Biol. Technol. 56 (4), 607-617. doi:10.1590/s151689132013000400011

Borges, F. T., Reis, L. A., and Schor, N. (2013). Extracellular Vesicles: Structure, Function, and Potential Clinical Uses in Renal Diseases. Braz. J. Med. Biol. Res. 46 (10), 824-830. doi:10.1590/1414-431x20132964

Chen, J.-y., An, R., Liu, Z.-j., Wang, J.-j., Chen, S.-z., Hong, M.-m., et al. (2014). Therapeutic Effects of Mesenchymal Stem Cell-Derived Microvesicles on Pulmonary Arterial Hypertension in Rats. Acta Pharmacol. Sin 35 (9), 1121-1128. doi:10.1038/aps.2014.61

Chen, Y.-T., Miao, K., Zhou, L., and Xiong, W.-N. (2021). Stem Cell Therapy for Chronic Obstructive Pulmonary Disease. Chin. Med. J. 134 (13), 1535-1545. doi: $10.1097 / \mathrm{cm} 9.0000000000001596$

de Faria, C. A., de las Heras Kozma, R., Stessuk, T., and Ribeiro-Paes, J. T. (2012). Experimental Basis and New Insights for Cell Therapy in Chronic Obstructive Pulmonary Disease. Stem Cel Rev Rep 8 (4), 1236-1244. doi:10.1007/s12015012-9410-7

Dong, B., Wang, C., Zhang, J., Zhang, J., Gu, Y., Guo, X., et al. (2021). Exosomes from Human Umbilical Cord Mesenchymal Stem Cells Attenuate the Inflammation of Severe Steroid-Resistant Asthma by Reshaping Macrophage Polarization. Stem Cel Res Ther 12 (1), 12. doi:10.1186/s13287-021-02244-6

Du, Y.-m., Zhuansun, Y.-x., Chen, R., Lin, L., Lin, Y., and Li, J.-g. (2018). Mesenchymal Stem Cell Exosomes Promote Immunosuppression of Regulatory T Cells in Asthma. Exp. Cel Res. 363 (1), 114-120. doi:10.1016/j. yexcr.2017.12.021

Eirin, A., and Lerman, L. O. (19792021). Mesenchymal Stem/Stromal Cell-Derived Extracellular Vesicles for Chronic Kidney Disease: Are We There yet? Hypertension 78 (2), 261-269. doi:10.1161/hypertensionaha.121.14596

Fang, S.-B., Zhang, H.-Y., Meng, X.-C., Wang, C., He, B.-X., Peng, Y.-Q., et al. (2020). Small Extracellular Vesicles Derived from Human MSCs Prevent Allergic Airway Inflammation via Immunomodulation on Pulmonary Macrophages. Cell Death Dis 11 (6). doi:10.1038/s41419-020-2606-x

Fang, S. B., Zhang, H. Y., Wang, C., He, B. X., Liu, X. Q., Meng, X. C., et al. (2020). Small Extracellular Vesicles Derived from Human Mesenchymal Stromal Cells Prevent Group 2 Innate Lymphoid Cell-dominant Allergic Airway Inflammation through Delivery of miR-146a-5p. J. extracellular vesicles 9 (1), 1723260. doi:10.1080/20013078.2020.1723260

Forum of International Respiratory Societies (2017). The Global Impact of Respiratory Disease. 2nd edn. Sheffield: European Respiratory Society Available at: https://wwwwhoint/gard/publications/The_Global_Impact_of_ Respiratory_Disease.pdf (Accessed Oct 24th, 2021).

Fu, S., Zhang, Y., Li, Y., Luo, L., Zhao, Y., and Yao, Y. (2020). Extracellular Vesicles in Cardiovascular Diseases. Cell Death Discov. 6 (1). doi:10.1038/s41420-02000305-y

\section{AUTHOR CONTRIBUTIONS}

All authors listed have made a substantial, direct, and intellectual contribution to the work and approved it for publication.

\section{FUNDING}

This work was supported by National Natural Science Foundation of China (No. 81873410, No. 81800043, and No.82070049), and Natural Science Foundation of Hunan Province (No.2020JJ5818).

Gao, Y., Sun, J., Dong, C., Zhao, M., Hu, Y., and Jin, F. (2020). Extracellular Vesicles Derived from Adipose Mesenchymal Stem Cells Alleviate PM2.5-Induced Lung Injury and Pulmonary Fibrosis. Med. Sci. Monit. 26, 26. doi:10.12659/msm. 922782

Gemoll, T., Strohkamp, S., Rozanova, S., Röder, C., Hartwig, S., Kalthoff, H., et al. (2020). Protein Profiling of Serum Extracellular Vesicles Reveals Qualitative and Quantitative Differences after Differential Ultracentrifugation and ExoQuick Isolation. Jcm 9 (5), 1429. doi:10.3390/jcm9051429

Herrmann, I. K., Wood, M. J. A., and Fuhrmann, G. (2021). Extracellular Vesicles as a Next-Generation Drug Delivery Platform. Nat. Nanotechnol. 16 (7), 748-759. doi:10.1038/s41565-021-00931-2

Hogan, S. E., Rodriguez Salazar, M. P., Cheadle, J., Glenn, R., Medrano, C., Petersen, T. H., et al. (2019). Mesenchymal Stromal Cell-Derived Exosomes Improve Mitochondrial Health in Pulmonary Arterial Hypertension. Am. J. Physiology-Lung Cell Mol. Physiol. 316 (5), L723-L737. doi:10.1152/ ajplung.00058.2018

Jalali, E., and Rabiee, M. (2016). Adipose Tissue Derived Mesenchymal Stem Cells. Iioab J. 7 (8), 112-118.

Khatri, M., Richardson, L. A., and Meulia, T. (2018). Mesenchymal Stem CellDerived Extracellular Vesicles Attenuate Influenza Virus-Induced Acute Lung Injury in a Pig Model. Stem Cel Res Ther 9 (1), 17. doi:10.1186/s13287-018 0774-8

Kim, D.-k., Nishida, H., An, S. Y., Shetty, A. K., Bartosh, T. J., and Prockop, D. J. (2016). Chromatographically Isolated CD63+CD81+ Extracellular Vesicles from Mesenchymal Stromal Cells rescue Cognitive Impairments after TBI. Proc. Natl. Acad. Sci. USA 113 (1), 170-175. doi:10.1073/pnas. 1522297113

Klinger, J. R., Pereira, M., Del Tatto, M., Brodsky, A. S., Wu, K. Q., Dooner, M. S., et al. (2020). Mesenchymal Stem Cell Extracellular Vesicles Reverse Sugen/ Hypoxia Pulmonary Hypertension in Rats. Am. J. Respir. Cel Mol Biol 62 (5), 577-587. doi:10.1165/rcmb.2019-0154OC

Lama, V. N., Smith, L., Badri, L., Flint, A., Andrei, A.-C., Murray, S., et al. (2007). Evidence for Tissue-Resident Mesenchymal Stem Cells in Human Adult Lung from Studies of Transplanted Allografts. J. Clin. Invest. 117 (4), 989-996. doi:10. $1172 /$ jci29713

Lasda, E., and Parker, R. (2016). Circular RNAs Co-precipitate with Extracellular Vesicles: A Possible Mechanism for circRNA Clearance. PloS one 11 (2), e0148407. doi:10.1371/journal.pone.0148407

Li, Y., Zhao, J., Yu, S., Wang, Z., He, X., Su, Y., et al. (2019). Extracellular Vesicles Long RNA Sequencing Reveals Abundant mRNA, circRNA, and lncRNA in Human Blood as Potential Biomarkers for Cancer Diagnosis. Clin. Chem. 65 (6), 798-808. doi:10.1373/clinchem.2018.301291

Linares, R., Tan, S., Gounou, C., Arraud, N., and Brisson, A. R. (2015). High-speed Centrifugation Induces Aggregation of Extracellular Vesicles. J. extracellular vesicles 4, 29509. doi:10.3402/jev.v4.29509

Liu, Z., Liu, J., Xiao, M., Wang, J., Yao, F., Zeng, W., et al. (2018). Mesenchymal Stem Cell-Derived Microvesicles Alleviate Pulmonary Arterial Hypertension by Regulating Renin-Angiotensin System. J. Am. Soc. Hypertens. 12 (6), 470-478. doi:10.1016/j.jash.2018.02.006

Livshits, M. A., Khomyakova, E., Evtushenko, E. G., Lazarev, V. N., Kulemin, N. A., Semina, S. E., et al. (2015). Isolation of Exosomes by Differential Centrifugation: Theoretical Analysis of a Commonly Used Protocol. Sci. Rep. 5, 17319. doi:10. 1038/srep 17319 
Maremanda, K. P., Sundar, I. K., and Rahman, I. (2019). Protective Role of Mesenchymal Stem Cells and Mesenchymal Stem Cell-Derived Exosomes in Cigarette Smoke-Induced Mitochondrial Dysfunction in Mice. Toxicol. Appl. Pharmacol. 385, 114788. doi:10.1016/j.taap.2019.114788

Momen-Heravi, F. (2017). Isolation of Extracellular Vesicles by Ultracentrifugation. In Methods in Molecular Biology, 1660. Clifton, NJ, 25-32. doi:10.1007/978-1-4939-7253-1_3

Monsel, A., Zhu, Y.-g., Gennai, S., Hao, Q., Hu, S., Rouby, J.-J., et al. (2015). Therapeutic Effects of Human Mesenchymal Stem Cell-Derived Microvesicles in Severe Pneumonia in Mice. Am. J. Respir. Crit. Care Med. 192 (3), 324-336. doi:10.1164/rccm.201410-1765OC

Pucci, F., Hamilton, N., Claudio, N., and Armstrong, R. (2021). Tumor-immune Communication via Extracellular Vesicles. Cancer Immunol. Res. 9 (2).

Ridzuan, N., Zakaria, N., Widera, D., Sheard, J., Morimoto, M., Kiyokawa, H., et al. (2021). Human Umbilical Cord Mesenchymal Stem Cell-Derived Extracellular Vesicles Ameliorate Airway Inflammation in a Rat Model of Chronic Obstructive Pulmonary Disease (COPD). Stem Cel Res Ther 12 (1), 12. doi:10.1186/s13287-020-02088-6

Sergejeva, S., Hoshino, H., Yoshihara, S., Kashimoto, K., Lötvall, J., and Lindén, A. (2004). A Synthetic VIP Peptide Analogue Inhibits Neutrophil Recruitment in Rat Airways In Vivo. Regul. peptides 117 (2), 149-154. doi:10.1016/j.regpep. 2003.10.002

Shao, H., Im, H., Castro, C. M., Breakefield, X., Weissleder, R., and Lee, H. (2018). New Technologies for Analysis of Extracellular Vesicles. Chem. Rev. 118 (4), 1917-1950. doi:10.1021/acs.chemrev.7b00534

Shi, M. m., Yang, Q. y., Monsel, A., Yan, J. y., Dai, C. x., Zhao, J. y., et al. (2021). Preclinical Efficacy and Clinical Safety of Clinical-grade Nebulized Allogenic Adipose Mesenchymal Stromal Cells-derived Extracellular Vesicles. J. extracellular vesicles 10 (10), e12134. doi:10.1002/jev2.12134

Soriano, J. B., Kendrick, P. J., Paulson, K. R., Gupta, V., Vos, T., Abrams, E. M., et al. (2020). Prevalence and Attributable Health burden of Chronic Respiratory Diseases, 1990-2017: a Systematic Analysis for the Global Burden of Disease Study 2017. Lancet Respir. Med. 8 (6), 585-596. doi:10.1016/S2213-2600(20) 30105-3

Théry, C., Witwer, K. W., Aikawa, E., Alcaraz, M. J., Anderson, J. D., Andriantsitohaina, R., et al. (2018). Minimal Information for Studies of Extracellular Vesicles 2018 (MISEV2018): a Position Statement of the International Society for Extracellular Vesicles and Update of the MISEV2014 Guidelines. J. Extracell Vesicles 7 (1), 1535750. doi:10.1080/ 20013078.2018.1535750

Tran, P. H. L., Duan, W., Lee, B.-J., and Tran, T. T. D. (2020). Current Perspectives on Delivery Systems Using Extracellular Vesicles in Neurological Disease. Cpd 26 (7), 764-771. doi:10.2174/1381612826666200102125847

Vagner, T., Chin, A., Mariscal, J., Bannykh, S., Engman, D. M., and Di Vizio, D. (2019). Protein Composition Reflects Extracellular Vesicle Heterogeneity. Proteomics 19 (8), 1800167. doi:10.1002/pmic.201800167

Vilaca, A., Sansonetti, M., Fernandes, H., de Windt, L., and Ferreira, L. (2021). Extracellular Vesicles as lncRNA-H19 Carriers to the Cardiovascular System. Eur. J. Clin. Invest. 51, 108-109.

Villamizar, O., Waters, S. A., Scott, T., Grepo, N., Jaffe, A., and Morris, K. V. (2021). Mesenchymal Stem Cell Exosome Delivered Zinc Finger Protein Activation of Cystic Fibrosis Transmembrane Conductance Regulator. J. extracellular vesicles 10 (3), 10. doi:10.1002/jev2.12053

Vu, L. T., Gong, J., Pham, T. T., Kim, Y., and Le, M. T. N. (2020). microRNA Exchange via Extracellular Vesicles in Cancer. Cell Prolif 53 (11), 53. doi:10. 1111/cpr.12877

Wan, X., Chen, S., Fang, Y., Zuo, W., Cui, J., and Xie, S. (2020). Mesenchymal Stem Cell-derived Extracellular Vesicles Suppress the Fibroblast Proliferation by
Downregulating FZD6 Expression in Fibroblasts via micrRNA-29b-3p in Idiopathic Pulmonary Fibrosis. J. Cel Physiol 235 (11), 8613-8625. doi:10. 1002/jcp.29706

Weiss, A. R. R., and Dahlke, M. H. (2019). Immunomodulation by Mesenchymal Stem Cells (MSCs): Mechanisms of Action of Living, Apoptotic, and Dead MSCs. Front. Immunol. 10, 1191. doi:10.3389/fimmu.2019.01191

World Health Organization Chronic Respiratory Diseases. Available at: https:// www.who.int/health-topics/chronic-respiratory-diseases\#tab=tab_1 (Accessed Oct 24th, 2021).

Xu, C., Zhao, J., Li, Q., Hou, L., Wang, Y., Li, S., et al. (2020). Exosomes Derived from Three-Dimensional Cultured Human Umbilical Cord Mesenchymal Stem Cells Ameliorate Pulmonary Fibrosis in a Mouse Silicosis Model. Stem Cel Res Ther 11 (1), 11. doi:10.1186/s13287-020-02023-9

Yang, J., Hu, H., Zhang, S., Jiang, L., Cheng, Y., Xie, H., et al. (2020). Human Umbilical Cord Mesenchymal Stem Cell-Derived Exosomes Alleviate Pulmonary Fibrosis in Mice by Inhibiting Epithelial-Mesenchymal Transition. Nan Fang $\mathrm{Yi} \mathrm{Ke} \mathrm{Da}$ Xue Xue BaoMEDLINE 40 (7), 98832895166-98832895994. doi:10.12122/j.issn.1673-4254.2020.07.11

Yuan, X., Li, D., Chen, X., Han, C., Xu, L., Huang, T., et al. (2017). Extracellular Vesicles from Human-Induced Pluripotent Stem Cell-Derived Mesenchymal Stromal Cells (hiPSC-MSCs) Protect against Renal Ischemia/reperfusion Injury via Delivering Specificity Protein (SP1) and Transcriptional Activating of Sphingosine Kinase 1 and Inhibiting Necroptosis. Cel Death Dis 8 (12), 3200. doi:10.1038/s41419-017-0041-4

Zhang, E., Geng, X., Shan, S., Li, P., Li, S., Li, W., et al. (2021). Exosomes Derived from Bone Marrow Mesenchymal Stem Cells Reverse Epithelial-Mesenchymal Transition Potentially via Attenuating Wnt/ $\beta$-Catenin Signaling to Alleviate Silica-Induced Pulmonary Fibrosis. Toxicol. Mech. Methods 31 (9), 655-666. doi:10.1080/15376516.2021.1950250

Zhang, S., Liu, X., Ge, L. L., Li, K., Sun, Y., Wang, F., et al. (2020). Mesenchymal Stromal Cell-Derived Exosomes Improve Pulmonary Hypertension through Inhibition of Pulmonary Vascular Remodeling. Respir. Res. 21 (1), 21. doi:10. 1186/s12931-020-1331-4

Zhou, J., Lin, Y., Kang, X., Liu, Z., Zhang, W., and Xu, F. (2021). microRNA-186 in Extracellular Vesicles from Bone Marrow Mesenchymal Stem Cells Alleviates Idiopathic Pulmonary Fibrosis via Interaction with SOX4 and DKK1. Stem Cel Res Ther 12 (1), 12. doi:10.1186/s13287-020-02083-x

Zulueta, A., Colombo, M., Peli, V., Falleni, M., Tosi, D., Ricciardi, M., et al. (2018). Lung Mesenchymal Stem Cells-Derived Extracellular Vesicles Attenuate the Inflammatory Profile of Cystic Fibrosis Epithelial Cells. Cell Signal. 51, 110-118. doi:10.1016/j.cellsig.2018.07.015

Conflict of Interest: The authors declare that the research was conducted in the absence of any commercial or financial relationships that could be construed as a potential conflict of interest.

Publisher's Note: All claims expressed in this article are solely those of the authors and do not necessarily represent those of their affiliated organizations, or those of the publisher, the editors, and the reviewers. Any product that may be evaluated in this article, or claim that may be made by its manufacturer, is not guaranteed or endorsed by the publisher.

Copyright (c) $2022 \mathrm{Ma}$, Liu, Long and Chen. This is an open-access article distributed under the terms of the Creative Commons Attribution License (CC BY). The use, distribution or reproduction in other forums is permitted, provided the original author(s) and the copyright owner(s) are credited and that the original publication in this journal is cited, in accordance with accepted academic practice. No use, distribution or reproduction is permitted which does not comply with these terms. 